\title{
POLÍTICAS PÚBLICAS DE BIBLIOTECA ESCOLAR NO BRASIL: O QUE OS PROGRAMAS DE PÓS-GRADUAÇÃO REVELAM
}

\author{
Fabiana Sala, Silvio César Nunes Militão
}

Universidade Estadual Paulista "Júlio de Mesquita Filho" - FCT-UNESP, Mestrado em Educação, Presidente Prudente, SP. E-mail: $\underline{\text { fabibuel@gmail.com }}$

\begin{abstract}
RESUMO
A biblioteca escolar é uma instituição dinâmica capaz de interagir com a escola e a comunidade. A efetivação de políticas públicas direcionadas às bibliotecas e a difusão da leitura representa a garantia do Estado de Direito ao princípio da igualdade. $\mathrm{O}$ artigo objetiva refletir sobre a maneira pela qual as principais leis nacionais que abordam a questão do livro, leitura e biblioteca no Brasil são discutidas nos programas de Pós-graduação em Educação e Ciência da Informação. A metodologia constou de pesquisa de natureza qualitativa, abrangendo revisão bibliográfica e análise documental. Os resultados demonstram que as pesquisas ainda são escassas e recentes e que esta área de estudo ainda tem muito para ser explorada, uma vez que, criar e promover bibliotecas escolares por meio de investimento público é o caminho apontado para que a população possa ter, de fato, espaços de informação e leitura capazes de promover a aquisição do conhecimento.
\end{abstract}

Palavras-chave: Políticas Públicas. Políticas Culturais. Leitura. Biblioteca Escolar. Democratização da Informação.

\section{PUBLIC POLICIES FOR SCHOOL LIBRARIES IN BRAZIL: WHAT THE POSTGRADUATE PROGRAMS REVEAL}

\section{ABSTRACT}

The school library is a dynamic institution capable of interacting with the school and the community. The enforcement of public policies directed to libraries and the dissemination of reading represents the guarantee of the rule of law the principle of equality. The article aims to reflect on the way in which the main national laws that address the issue of the book, reading room and library in Brazil are discussed in the post-graduate programs in Education and Information Science. The methodology consisted of qualitative research, covering literature review and documentary analysis. The results show that the research are still scarce and recent and that this area of study still has much to be explored, since, create and promote school libraries through public investment is the path indicated that the population is likely to have, in fact, spaces of information and reading capable of promoting the acquisition of knowledge

Keywords: Public Politics; Cultural Politics; Reading. School Library. Democratization of Information.

\section{INTRODUÇÃO}

A Biblioteca escolar se constitui em um espaço de aprendizagem por excelência quando desenvolvidas ações que devem estar em consonância com os objetivos delineados pela escola. Dentre as ações consideradas por Campello (2003), relevantes para a formação do aluno, aquelas voltadas para o incentivo à leitura e o letramento informacional, aliada ao desenvolvimento do senso ético e cidadão conforme concepção de Morigi, Vanz e Galdino (2015) são efetivamente as que possuem cunho de ação pedagógica na biblioteca escolar, visto que possibilita o aluno 
desenvolver e/ou ampliar o interesse pela leitura, a capacidade de compreensão da necessidade, localização, seleção e interpretação da informação de forma crítica e responsável.

Para que ocorra a promoção da biblioteca escolar é necessário envolvimento político e articulação entre o governo federal, estados, municípios e a sociedade civil, a fim de instituir políticas públicas e programas que resgatem o papel da biblioteca escolar na formação da sociedade.

A biblioteca, instituição milenar que durante séculos garantiu a sobrevivência dos registros do conhecimento humano, tem agora seu potencial reconhecido como partícipe fundamental do complexo processo educacional. Pois pode contribuir efetivamente para preparar crianças e jovens para viver no mundo contemporâneo, em que informação e conhecimento assumem destaque central (ANDRADE, 2008, p. 15).

A efetivação de políticas públicas direcionadas às bibliotecas e a difusão da leitura representa a garantia do Estado de Direito ao princípio da igualdade. O artigo objetiva refletir sobre a maneira pela qual as principais leis nacionais que abordam a questão do livro, leitura e biblioteca no Brasil são discutidas nos programas de Pós-graduação em Educação e Ciência da Informação, a fim de traçar um panorama do conhecimento sobre a temática em estudo.

\section{METODOLOGIA}

Em relação aos procedimentos metodológicos visando à coleta e análise de dados, optouse pela pesquisa qualitativa, abrangendo revisão bibliográfica e análise documental, representados por teses e dissertações defendidas em programas de Pós-graduação em Educação e Ciência da Informação com conceitos 4, 5, 6 e 7. Os programas foram selecionados por conceitos de acordo com os dados obtidos na Plataforma Sucupira. Os descritores utilizados na busca pelas produções acadêmicas foram: "Biblioteca Escolar"; "Política Pública de Biblioteca" e "Política Pública de Leitura".

\section{RESULTADOS}

Inicialmente a pesquisa foi realizada por meio da leitura dos títulos, resumos e palavraschave dos trabalhos disponíveis nos bancos de teses e dissertações dos programas de Pósgraduação selecionados. Ao todo foram consultados 101 publicações, entre dissertações e teses.

Após essa primeira análise, selecionamos 29 produções, sendo elas, 14 dissertações e 04 teses de Programas de Pós-graduação em Educação e 11 dissertações em Programas de Pósgraduação em Ciência da Informação. Dentre os trabalhos selecionados, não houve nenhuma ocorrência de tese em Programas de Pós-graduação em Ciência da Informação.

Ao selecionar os 29 trabalhos, o levantamento não considerou os trabalhos cujo acesso ao texto não estavam disponíveis no momento da pesquisa. A pesquisa também não delimitou um período específico para seleção dos trabalhos. Todas as produções localizadas foram consideradas, independente do ano de publicação.

No entanto, conforme pode ser observado na tabela 1, apesar do levantamento bibliográfico não delimitar período, nota-se que, os trabalhos selecionados são recentes pois, os mais antigos datam de 2005.

Tabela 1 - Distribuição anual das teses e dissertações selecionadas

\begin{tabular}{l|ll}
\hline \multicolumn{1}{c|}{ Ano } & \multicolumn{1}{c}{ Frequência } \\
\hline 2005 & 2 & \\
2006 & 3 & \\
2007 & 2 &
\end{tabular}




\begin{tabular}{ll}
2008 & 4 \\
2009 & 0 \\
2010 & 2 \\
2011 & 1 \\
2012 & 2 \\
2013 & 2 \\
2014 & 3 \\
2015 & 4 \\
2016 & 4 \\
\hline TOTAL & 29 \\
\hline
\end{tabular}

Fonte: Organizada pelos autores.

Observa-se nesta tabela que, o número de produções acadêmicas que envolvem a temática em estudo ainda é bastante limitado, o que pode ser considerado, de acordo com Oliveira e Prados (2015), como o reflexo da não eficiência das políticas públicas de leitura e biblioteca escolar no país. "Com relação à atuação do Estado nas políticas públicas para o livro, leitura, literatura e biblioteca, podemos considerar essa atuação como tímida ao longo do tempo" (OLIVEIRA; PRADOS, 2015, p. 103).

Destaca-se que, no ano de 2009, não houve nenhum trabalho defendido e a maior frequência identificada foram de apenas 4 trabalhos nos anos de 2008, 2015 e 2016. Números ainda muito modestos mas que podem ser bastante significativos ao constatarmos que no ano de 2013 foram 3 trabalhos (um a mais que os anos anteriores) e que 2015 e 2016 também tiveram um aumento de interesse.

Fato que pode estar relacionado à Lei n. 12.244 de 24 de maio de 2010 que "Dispõe sobre a universalização das bibliotecas nas instituições de ensino do País" e dá o prazo de 10 anos para que as instituições de ensino públicas e privadas de todos os sistemas de ensino do país se adequem para que a universalização das bibliotecas escolares sejam efetivadas. Uma vez que o prazo está se esgotando, supõe-se que, cresce o interesse em investigar como os sistemas de ensino estão se organizando para o cumprimento e efetivação da lei.

A tabela 2 apresenta a distribuição das Instituições em que foram defendidas as teses e dissertações, totalizando 13 ocorrência.

Tabela 2 - Distribuição da instituições onde foram defendidas as teses e dissertações

\begin{tabular}{l|l}
\hline \multicolumn{1}{r}{ Instituição } & \multicolumn{1}{c}{ Frequência } \\
\hline UNB & 7 \\
PUC/SP & 3 \\
UNESP/MAR & 3 \\
UNICAMP & 3 \\
USP & 3 \\
UFSC & 2 \\
UNESP/PP & 2 \\
PUC/CAMP & 1 \\
UFMT & 1 \\
UFPR & 1 \\
UMESP & 1 \\
UNIRIO & 1 \\
USF & 1 \\
\hline TOTAL & 29 \\
\hline
\end{tabular}

Fonte: Organizada pelos autores. 
Observa-se que, apesar de terem sido selecionadas para a pesquisa um total de 72 Instituições com programas de Pós-graduação em Educação e 10 Instituições com programas de Pós-graduação em Ciência da Informação, apenas 13 Instituições apresentaram produções acadêmicas de acordo com os descritores selecionados. A maior parte dos trabalhos são de Universidades localizadas na região Sudeste (15 dissertações e 03 teses), seguida pela região Centro-Oeste (08 dissertações) e por fim, a região Sul (02 dissertações e 01 tese).

Os dados apontam também um desequilíbrio na distribuição dos trabalhos por nível (tese/dissertação). Identifica-se que há uma preferência nos programas de Pós-graduação por desenvolver pesquisas em nível de mestrado, em detrimento as pesquisas que são realizadas em nível de doutorado que somam apenas 4 em um total de 29 pesquisas, conforme segue: 2005 (02 dissertações); 2006 (01 dissertação e 02 teses); 2007 (02 dissertações); 2008 (04 dissertações); 2009 (00); 2010 (02 dissertações); 2011 (01 dissertação); 2012 (02 dissertações); 2013 (02 dissertações); 2014 (01 dissertação e 02 teses); 2015 (04 dissertações) e 2016 (04 dissertações).

Para detalhamento das produções, organizamos os seguintes quadros com suas principais informações. Separamos os quadros por programas (Educação e Ciência da Informação).

Quadro 1 - Teses e dissertações selecionadas em programas de pós-graduação em educação

\begin{tabular}{|c|c|c|c|c|}
\hline Ano & Nível & IES & Título & Autor \\
\hline 2005 & $\begin{array}{l}\text { Mestrad } \\
\text { o }\end{array}$ & $\begin{array}{l}\text { Universidade } \\
\text { Federal de Santa } \\
\text { Catarina (UFSC) }\end{array}$ & $\begin{array}{l}\text { Informação pública e consciência } \\
\text { crítica para cidadania: políticas } \\
\text { públicas de informação em } \\
\text { Blumenau }\end{array}$ & $\begin{array}{l}\text { SILVA, Sandra } \\
\text { Cristina da }\end{array}$ \\
\hline 2006 & $\begin{array}{l}\text { Doutorad } \\
\text { o }\end{array}$ & $\begin{array}{l}\text { Pontifícia } \\
\text { universidade } \\
\text { Católica (PUC/SP) }\end{array}$ & $\begin{array}{l}\text { Sala de leitura nas escolas da rede } \\
\text { municipal de ensino de São Paulo: } \\
\text { uma inovação que resiste às } \\
\text { descontinuidades políticas }\end{array}$ & $\begin{array}{l}\text { MENDES, } \\
\text { Mônica Fátima } \\
\text { Valenzi }\end{array}$ \\
\hline 2006 & $\begin{array}{l}\text { Doutorad } \\
\text { o }\end{array}$ & $\begin{array}{l}\text { Universidade } \\
\text { Estadual Paulista } \\
\text { (UNESP/MAR) } \\
\end{array}$ & $\begin{array}{l}\text { O professor mediador de leitura na } \\
\text { biblioteca escolar da rede municipal } \\
\text { de Londrina: formação e atuação }\end{array}$ & $\begin{array}{l}\text { SILVA, Rovilson } \\
\text { José da }\end{array}$ \\
\hline 2006 & $\begin{array}{l}\text { Mestrad } \\
\text { o }\end{array}$ & $\begin{array}{l}\text { Universidade } \\
\text { Estadual de } \\
\text { Campinas } \\
\text { (UNICAMP) }\end{array}$ & $\begin{array}{l}\text { Leitura e envolvimento: a escola, a } \\
\text { biblioteca e o professor na } \\
\text { construção das relações entre } \\
\text { leitores e livros }\end{array}$ & $\begin{array}{l}\text { KLEBIS, Carlos } \\
\text { Eduardo de } \\
\text { Oliveira }\end{array}$ \\
\hline 2007 & $\begin{array}{l}\text { Mestrad } \\
\text { o }\end{array}$ & $\begin{array}{l}\text { Universidade } \\
\text { Federal do Mato } \\
\text { Grosso (UFMT) } \\
\end{array}$ & $\begin{array}{l}\text { Biblioteca escolar: espaço cultural } \\
\text { que pode contribuir para o processo } \\
\text { de letramento }\end{array}$ & $\begin{array}{l}\text { GARCIA, Lígia } \\
\text { Vieira }\end{array}$ \\
\hline 2007 & $\begin{array}{l}\text { Mestrad } \\
0\end{array}$ & $\begin{array}{l}\text { Universidade de } \\
\text { São Paulo (USP) }\end{array}$ & $\begin{array}{l}\text { Biblioteca escolar: um espaço } \\
\text { necessário para leitura na escola }\end{array}$ & $\begin{array}{l}\text { ALONSO, } \\
\text { Claudia Maria } \\
\text { Rodrigues }\end{array}$ \\
\hline 2008 & $\begin{array}{l}\text { Mestrad } \\
\text { o }\end{array}$ & $\begin{array}{l}\text { Pontifícia } \\
\text { Universidade } \\
\text { Católica (PUC/SP) }\end{array}$ & $\begin{array}{l}\text { O Departamento Municipal de } \\
\text { Cultura de São Paulo (1935-1938): } \\
\text { políticas de criação de bibliotecas e } \\
\text { democratização de leitura }\end{array}$ & $\begin{array}{l}\text { GOMES, } \\
\text { Denise } \\
\text { Pedroso }\end{array}$ \\
\hline 2008 & $\begin{array}{l}\text { Mestrad } \\
\text { o }\end{array}$ & $\begin{array}{l}\text { Universidade } \\
\text { Metodista de São } \\
\text { Paulo (UMESP) } \\
\end{array}$ & $\begin{array}{l}\text { Políticas públicas voltadas para a } \\
\text { formação do leitor: o projeto hora } \\
\text { da leitura }\end{array}$ & $\begin{array}{l}\text { MENEGHET, } \\
\text { Marinês Lopes } \\
\text { Fernandes }\end{array}$ \\
\hline 2010 & $\begin{array}{l}\text { Mestrad } \\
\text { o }\end{array}$ & $\begin{array}{l}\text { Universidade de } \\
\text { Brasília (UNB) }\end{array}$ & $\begin{array}{l}\text { Política de leitura: a gestão do } \\
\text { programa federal Literatura em } \\
\text { minha casa }\end{array}$ & $\begin{array}{l}\text { MORAIS, } \\
\text { Lucimara } \\
\text { Gomes }\end{array}$ \\
\hline
\end{tabular}

Colloquium Socialis, Presidente Prudente, v. 01, n. Especial 2, Jul/Dez, 2017, p.801-808. DOI: 10.5747/cs.2017.v01.nesp2.s0231 


\begin{tabular}{|c|c|c|c|c|}
\hline & & & & Oliveira de \\
\hline 2010 & $\begin{array}{l}\text { Mestrad } \\
\text { o }\end{array}$ & $\begin{array}{l}\text { Universidade } \\
\text { Estadual Paulista } \\
\text { (UNESP/PP) }\end{array}$ & $\begin{array}{l}\text { Biblioteca escolar e políticas públicas } \\
\text { de incentivo à leitura: de museu de } \\
\text { livro a espaço de saber e leitura }\end{array}$ & $\begin{array}{l}\text { GUIMARÃES } \\
\text { Janaína }\end{array}$ \\
\hline 2011 & $\begin{array}{l}\text { Mestrad } \\
\text { o }\end{array}$ & $\begin{array}{l}\text { Universidade } \\
\text { Estadual de } \\
\text { Campinas } \\
\text { (UNICAMP) }\end{array}$ & $\begin{array}{l}\text { A leitura e a biblioteca escolar: o } \\
\text { caso da rede estadual de São Paulo }\end{array}$ & $\begin{array}{l}\text { CARVALHO, } \\
\text { Valdirene } \\
\text { Rodrigues de }\end{array}$ \\
\hline 2012 & $\begin{array}{l}\text { Mestrad } \\
\text { o }\end{array}$ & $\begin{array}{l}\text { Universidade São } \\
\text { Francisco (USF) }\end{array}$ & $\begin{array}{l}\text { O Poder da biblioteca nos processos } \\
\text { de (in)visibilidade do saber: um } \\
\text { estudo de caso sobre a EJA }\end{array}$ & $\begin{array}{l}\text { LIMA, Maria } \\
\text { Aparecida } \\
\text { Ferreira de }\end{array}$ \\
\hline 2013 & $\begin{array}{l}\text { Mestrad } \\
\text { o }\end{array}$ & $\begin{array}{l}\text { Universidade de } \\
\text { Brasília (UNB) }\end{array}$ & $\begin{array}{l}\text { Política de leitura: a coleção } \\
\text { "literatura para todos" e o } \\
\text { letramento literário de jovens e } \\
\text { adultos }\end{array}$ & $\begin{array}{l}\text { OGLIARI, } \\
\text { Monalisa }\end{array}$ \\
\hline 2013 & $\begin{array}{l}\text { Mestrad } \\
\text { o }\end{array}$ & $\begin{array}{l}\text { Universidade } \\
\text { Estadual de } \\
\text { Campinas } \\
\text { (UNICAMP) }\end{array}$ & $\begin{array}{l}\text { A biblioteca escolar na produção } \\
\text { acadêmica sobre leitura: } \\
\text { movimentos, diálogos, } \\
\text { aproximações }\end{array}$ & $\begin{array}{l}\text { ALIAGA, } \\
\text { Renata }\end{array}$ \\
\hline 2014 & $\begin{array}{l}\text { Doutorad } \\
\text { o }\end{array}$ & $\begin{array}{l}\text { Universidade } \\
\text { Estadual Paulista } \\
\text { (UNESP/PP) } \\
\end{array}$ & $\begin{array}{l}\text { Bibliotecas Escolares de Rio Verde- } \\
\text { GO: uma possível política municipal } \\
\text { de leitura }\end{array}$ & $\begin{array}{l}\text { LOPES, } \\
\text { Leonardo } \\
\text { Montes } \\
\end{array}$ \\
\hline 2014 & $\begin{array}{l}\text { Doutorad } \\
\text { o }\end{array}$ & $\begin{array}{l}\text { Universidade } \\
\text { Federal do Paraná } \\
\text { (UFPR) }\end{array}$ & $\begin{array}{l}\text { Contribuições da práxis para a } \\
\text { constituição da biblioteca escolar do } \\
\text { trabalho a partir da educação do } \\
\text { campo }\end{array}$ & $\begin{array}{l}\text { GEHRKE, } \\
\text { Marcos }\end{array}$ \\
\hline 2015 & $\begin{array}{l}\text { Mestrad } \\
\text { o }\end{array}$ & $\begin{array}{l}\text { Universidade } \\
\text { Federal de Santa } \\
\text { Catarina (UFSC) } \\
\end{array}$ & $\begin{array}{l}\text { Políticas públicas para o livro e a } \\
\text { leitura no Brasil: acervos para os } \\
\text { anos iniciais do ensino fundamental }\end{array}$ & $\begin{array}{l}\text { SOUZA, } \\
\text { Ingobert } \\
\text { Vargas de }\end{array}$ \\
\hline 2016 & $\begin{array}{l}\text { Mestrad } \\
\text { o }\end{array}$ & $\begin{array}{l}\text { Pontifícia } \\
\text { Universidade } \\
\text { Católica (PUC/SP) }\end{array}$ & $\begin{array}{l}\text { Da biblioteca escolar à sala de } \\
\text { leitura nas escolas estaduais de } \\
\text { Ensino Fundamental paulista: leis, } \\
\text { decretos, normas, agentes }\end{array}$ & $\begin{array}{l}\text { LIMA, Maria } \\
\text { Cecília Rizzi }\end{array}$ \\
\hline
\end{tabular}

Fonte: Organizado pelos autores.

Quadro 2 - Dissertações selecionadas em programas de pós-graduação em ciência da informação

\begin{tabular}{|l|l|l|l|l|}
\hline Ano & Nível & IES & Título & Autor \\
\hline 2005 & $\begin{array}{l}\text { Mestrad } \\
\text { o }\end{array}$ & $\begin{array}{l}\text { Pontifícia } \\
\text { Universidade } \\
\text { Católica } \\
\text { (PUC/CAMP) }\end{array}$ & $\begin{array}{l}\text { A trajetória dos programas oficiais } \\
\text { de leitura e da biblioteca pública no } \\
\text { Brasil durante o período 1937-2004 }\end{array}$ & $\begin{array}{l}\text { CALDAS, Elaine } \\
\text { Formentini }\end{array}$ \\
\hline 2008 & $\begin{array}{l}\text { Mestrad } \\
\text { Oniversidade de } \\
\text { Brasília (UNB) }\end{array}$ & $\begin{array}{l}\text { A função da biblioteca pública } \\
\text { escolar no contexto da formação } \\
\text { integral do educando: estudo de } \\
\text { caso }\end{array}$ & $\begin{array}{l}\text { AMARAL, } \\
\text { Renilda } \\
\text { Gonçalves do }\end{array}$ \\
\hline 2012 & $\begin{array}{l}\text { Mestrad } \\
\text { Mestrad }\end{array}$ & $\begin{array}{l}\text { Universidade de São } \\
\text { Paulo (USP) }\end{array}$ & $\begin{array}{l}\text { Leitura mediada na biblioteca } \\
\text { escolar: uma experiência em escola } \\
\text { pública }\end{array}$ & $\begin{array}{l}\text { FERRAZ, Marta } \\
\text { Maria Pinto }\end{array}$ \\
\hline
\end{tabular}

Colloquium Socialis, Presidente Prudente, v. 01, n. Especial 2, Jul/Dez, 2017, p.801-808. DOI: 10.5747/cs.2017.v01.nesp2.s0231 


\begin{tabular}{|c|c|c|c|c|}
\hline & 0 & $\begin{array}{l}\text { Estadual Paulista } \\
\text { (UNESP/MAR) }\end{array}$ & $\begin{array}{l}\text { informação e comunicação em } \\
\text { bibliotecas escolares em busca de } \\
\text { um espaço dinâmico }\end{array}$ & $\begin{array}{l}\text { Lucirene } \\
\text { Andrea Catini }\end{array}$ \\
\hline 2014 & $\begin{array}{l}\text { Mestrad } \\
0\end{array}$ & $\begin{array}{l}\text { Universidade de São } \\
\text { Paulo (USP) }\end{array}$ & $\begin{array}{l}\text { Bibliotecas escolares: políticas } \\
\text { públicas para a criação de } \\
\text { possibilidades }\end{array}$ & VIANA, Lilian \\
\hline 2015 & $\begin{array}{l}\text { Mestrad } \\
0\end{array}$ & $\begin{array}{l}\text { Universidade de } \\
\text { Brasília (UNB) }\end{array}$ & $\begin{array}{l}\text { As representações sociais no ensino } \\
\text { médio do Distrito Federal: a } \\
\text { biblioteca escolar pública sob o olhar } \\
\text { do estudante }\end{array}$ & $\begin{array}{l}\text { DUARTE, } \\
\text { Yaciara } \\
\text { Mendes }\end{array}$ \\
\hline 2015 & $\begin{array}{l}\text { Mestrad } \\
0\end{array}$ & $\begin{array}{l}\text { Universidade de } \\
\text { Brasília (UNB) }\end{array}$ & $\begin{array}{l}\text { A biblioteca escolar nos projetos de } \\
\text { leitura nas escolas que obtiveram os } \\
\text { melhores resultados do Enem }\end{array}$ & $\begin{array}{l}\text { SILVESTRE } \\
\text { ESTELA, Flor } \\
\text { de María }\end{array}$ \\
\hline 2015 & $\begin{array}{l}\text { Mestrad } \\
0\end{array}$ & $\begin{array}{l}\text { Universidade de } \\
\text { Brasília (UNB) }\end{array}$ & $\begin{array}{l}\text { Políticas de Estado e bibliotecas } \\
\text { públicas: um estudo de caso do } \\
\text { Plano Distrital do Livro e da Leitura }\end{array}$ & $\begin{array}{l}\text { MACHADO, } \\
\text { Frederico } \\
\text { Borges }\end{array}$ \\
\hline 2016 & $\begin{array}{l}\text { Mestrad } \\
0\end{array}$ & $\begin{array}{l}\text { Universidade de } \\
\text { Brasília (UNB) }\end{array}$ & $\begin{array}{l}\text { Desenvolvimento e políticas } \\
\text { públicas: análise da 'formação } \\
\text { cidadã' no âmbito do PNLD (2015- } \\
\text { 2017) }\end{array}$ & $\begin{array}{l}\text { QUARESMA } \\
\text { NETO, João } \\
\text { Rodrigues }\end{array}$ \\
\hline 2016 & $\begin{array}{l}\text { Mestrad } \\
\text { o }\end{array}$ & $\begin{array}{l}\text { Universidade } \\
\text { Federal do Estado } \\
\text { do Rio de Janeiro } \\
\text { (UNIRIO) }\end{array}$ & $\begin{array}{l}\text { A aplicação da Lei no } 12.244 / 2010 \text { na } \\
\text { Rede Pública Municipal de Ensino } \\
\text { Fundamental de Niterói: situação e } \\
\text { perspectivas } \\
\text { das bibliotecas escolares }\end{array}$ & $\begin{array}{l}\text { COSTA, Valéria } \\
\text { Souza da }\end{array}$ \\
\hline 2016 & $\begin{array}{l}\text { Mestrad } \\
0\end{array}$ & $\begin{array}{l}\text { Universidade } \\
\text { Estadual Paulista } \\
\text { (UNESP/MAR) }\end{array}$ & $\begin{array}{l}\text { O profissional da informação na } \\
\text { elaboração de políticas públicas: } \\
\text { uma análise do Plano Nacional do } \\
\text { Livro e da Leitura (PNLL) }\end{array}$ & $\begin{array}{l}\text { MARSULO, } \\
\text { Thabyta } \\
\text { Giraldell }\end{array}$ \\
\hline
\end{tabular}

Fonte: Organizado pelos autores.

\section{DISCUSSÃO}

Para uma análise mais criteriosa, as pesquisas foram divididas em dois grupos, de acordo com a similaridade e enfoque dado ao objeto de análise de cada trabalho estudado.

No primeiro grupo, selecionamos os trabalhos que abordam as políticas e programas de incentivo à leitura e promoção da biblioteca escolar. Neste grupo encontra-se um total de 17 pesquisas que se assemelham por dar ênfase ao estudo de elaboração/implementação de políticas e programas governamentais sobre leitura e biblioteca escolar, são eles: SILVA, 2005; CALDAS, 2005; MENDES, 2006; "GOMES, 2008; MENEGUET, 2008; MORAIS, 2010; GUIMARAES, 2010; CARVALHO, 2011; OGLIARI, 2013; LOPES, 2014; VIANA, 2014; SOUZA, 2015; MACHADO, 2015; LIMA, 2016; QUARESMA NETO, 2016; COSTA, 2016 e MARSULO, 2016.

Desses 17 trabalhos, 11 faz parte de Programas de Pós-Graduação em Educação e 06 faz parte de Programas de Pós-Graduação em Ciência da Informação. Esses estudos estão preocupados em abordar a questão da relação existente entre leitura e cidadania, conforme destaca Oliveira e Prados (2015, p. 103), "A leitura permite que o cidadão desenvolva uma consciência crítica a respeito de si e da sociedade... a leitura é um direito humano que proporciona o exercício pleno da democracia... quando lemos questionamos o mundo e a nós mesmos".

O segundo grupo compreende os trabalhos que abordam o papel da biblioteca escolar e suas ações na formação do leitor e da sociedade. Neste grupo encontra-se um total de 12 
trabalhos que se assemelham por dar enfoque ao papel da biblioteca escolar e a importância das atividades de mediação na formação do aluno/leitor, conforme afirma Campello, (2010, p. 26):

A biblioteca da escola é o espaço, por excelência, para o desenvolvimento de atividades de produção do conhecimento, que colocam o aluno no centro do processo de aprendizagem. Uma das mudanças mais significativas que o professor interessado em desenvolver esse tipo de atividade vai enfrentar é o trabalho em colaboração. O bibliotecário da escola pode ser um parceiro nesse processo por estar acostumado a ver a boa biblioteca como um espaço de construção do conhecimento.

Desses 12 trabalhos, 07 faz parte de Programas de Pós-Graduação em Educação e 05 faz parte de Programas de Pós-Graduação em Ciência da Informação, são eles: SILVA, 2006; KLEBIS, 2006; GARCIA, 2007; ALONSO, 2007; AMARAL, 2008; FERRAZ, 2008; LANZI, 2012; LIMA, 2012; ALIAGA, 2013; GEHRKE, 2014; DUARTE, 2015 e SILVESTRE ESTELA, 2015.

\section{CONCLUSÃO}

Após explanação dos objetivos e resultados das pesquisas selecionadas nos bancos de dados dos programas de Pós-Graduação analisados, pode-se constatar que as pesquisas que tem como foco de estudo a biblioteca escolar e as políticas públicas de leitura e informação ainda são escassas e recentes. Dos 29 trabalhos analisados, a data de conclusão mais antiga é do ano de 2005.

Os dados apontam ainda um desequilíbrio na distribuição dos trabalhos por nível (tese/dissertação). Identifica-se que há uma preferência nos programas de Pós-graduação em Educação e Ciência da Informação por desenvolver pesquisas em nível de mestrado, em detrimento as pesquisas que são realizadas em nível de doutorado que somam apenas 4 em um total de 25 pesquisas selecionadas.

Desse modo, além da contribuição e relevância que os resultados dessas pesquisas revelam, esse levantamento bibliográfico demonstra também que essa área de estudo ainda tem muito para ser explorada, uma vez que, criar e promover bibliotecas escolares por meio de investimento público é o caminho apontado para que a população possa ter, de fato, espaços de informação e leitura capazes de promover a aquisição do conhecimento, com foco no direito fundamental à informação. Pois, somente por meio de mudança política, discursiva e institucional será possível uma transformação bem-sucedida no cenário da leitura e biblioteca escolar no Brasil.

\section{REFERÊNCIAS BIBLIOGRÁFICAS}

ANDRADE, Maria Eugênia Albino. A biblioteca faz a diferença. In: Campello, Bernadete Santos et. al. A biblioteca escolar: temas para uma prática pedagógica. 2. ed. Belo Horizonte: Autentica, 2008.

CAMPELLO, Bernadete. A função educativa da biblioteca escolar no Brasil: perspectivas para o seu aperfeiçoamento. In: ENCONTRO NACIONAL DE PESQUISA EM CIÊNCIA DA INFORMAÇÃO, 5., 2003a, Belo Horizonte. Anais... Belo Horizonte: Escola de Ciência da Informação da UFMG, 2003.

CAMPELLO, Bernadete. O bibliotecário e a pesquisa escolar. Presença Pedagógica, v. 16, n. 93, maio/jun. 2010.

MORIGI, Valdir José Samile; VANZ, Andréa de Souza; GALDINO, Karina. O bibliotecário e suas práticas na construção da cidadania. Revista ACB: biblioteconomia em Santa Catarina, v.7, n.2, 
2002. Disponível em: <http://revista.acbsc.org.br/index.php/racb/article/view/390/480>. Acesso em: 9 julho 2015.

OLIVEIRA, A. D.; PRADOS, R. M. N. Políticas públicas para o livro, leitura e biblioteca no Brasil. Información, Cultura y Sociedad, Buenos Aires, v. 32, p. 99-112, jun. 2015. 